\title{
Nifedipine-Induced Gingival Hypertrophy
}

\author{
Masami Matsumura ${ }^{1}$, Yasunori Suzuki ${ }^{2}$, Masakazu Yamagishi ${ }^{3}$ and Mitsuhiro Kawano ${ }^{2}$
}

Key words: nifedipine, gingival hypertrophy

(Intern Med 51: 121, 2012)

(DOI: 10.2169/internalmedicine.51.6626)

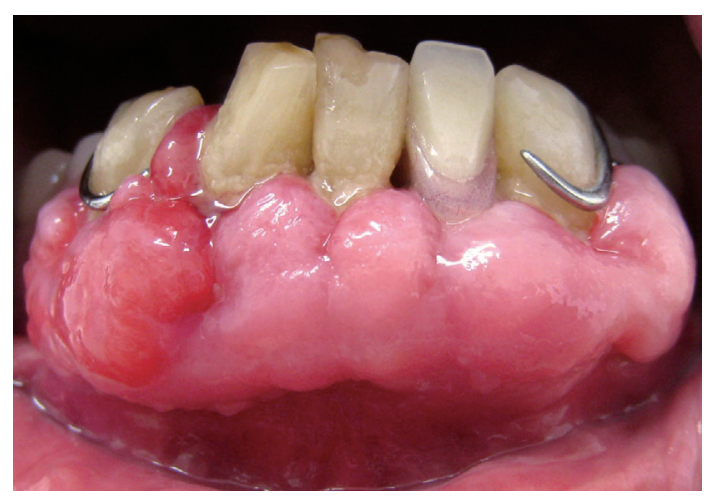

Picture 1.

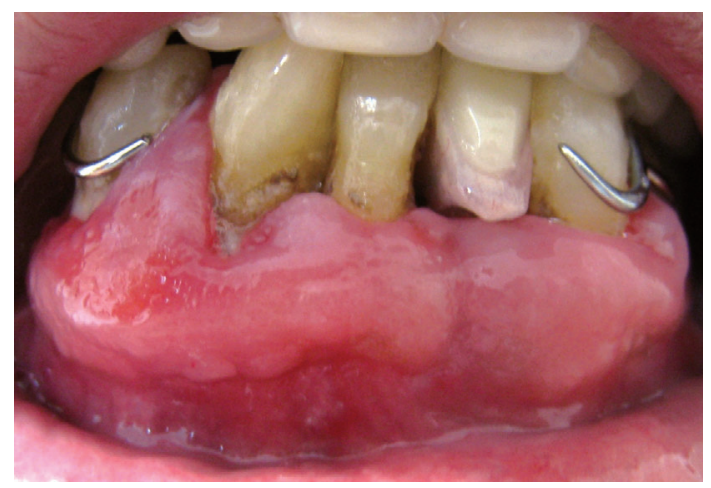

Picture 2.

A 55-year-old man was referred to us because of renal dysfunction (serum creatinine $1.82 \mathrm{mg} / \mathrm{dL}$ ). Three years earlier, he had aortic dissection associated with left renal artery occlusion and had undergone surgery for ascending aorta and aortic arch replacement. He had been receiving the following medications for 3 years; nifedipine (Adalat-CR) 40

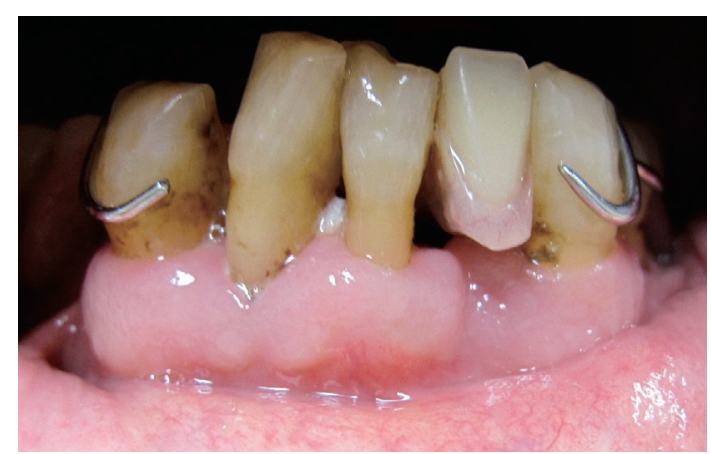

Picture 3.

$\mathrm{mg}$, carvedilol $10 \mathrm{mg}$, aspirin $100 \mathrm{mg}$, allopurinol $200 \mathrm{mg}$, and famotidine $10 \mathrm{mg}$ daily. Examination revealed severe gingival hypertrophy with bleeding (Picture 1). These manifestations prevented him from tooth brushing. We substituted losartan potassium $25 \mathrm{mg}$ daily for nifedipine. Gingival hypertrophy improved 4 months later (Picture 2) and it was resolved 3 years after nifedipine withdrawal (Picture 3). Calcium channel blockers, phenytoin, and cyclosporin are known to cause gingival hypertrophy. The mechanisms are still unclear. Cessation of the drug or meticulous plaque control is recommended for treatment (1). We should not overlook this adverse event which can cause an unpleasant odor, bleeding, infections, or eating difficulty (1).

The authors state that they have no Conflict of Interest (COI).

\section{Reference}

1. Sucu M, Yuce M, Davutoglu V. Amlodipine-induced massive gingival hypertrophy. Can Fam Physician 57: 436-437, 2011.

\footnotetext{
${ }^{1}$ Research Center for Medical Education, Kanazawa University Graduate School of Medicine, Japan, ${ }^{2}$ Division of Rheumatology, Department of Internal Medicine, Kanazawa University Graduate School of Medicine, Japan and ${ }^{3}$ Division of Cardiology, Department of Internal Medicine, Kanazawa University Graduate School of Medicine, Japan

Received for publication September 26, 2011; Accepted for publication September 30, 2011

Correspondence to Dr. Masami Matsumura, mmatsu@ spacelan.ne.jp

(C) 2012 The Japanese Society of Internal Medicine Journal Website: http://www.naika.or.jp/imindex.html
} 